\title{
A Note on Endogenous Transfers
}

\author{
By \\ Steven Brakman, Groningen, The Netherlands, and \\ Charles van Marrewijk, Rotterdam, The Netherlands*
}

(Received January 30, 1991; revised version received June 20, 1991)

In a competitive and Walrasian stable world with two goods transfer paradoxes are very robust to endogenization (relating the size of the transfer to either the donor's or the recipient's GNP). Donor enrichment and/or recipient impoverishment occur in very general formulations of endogenization if and only if they occur in the model in which transfers are exogenous (as is usually assumed). Endogenization in practice will probably cause a dampening effect (smaller price and welfare changes than in the case of pure exogenous transfers).

\section{Introduction}

Transfer paradoxes, i.e. donor enrichment and/or recipient impoverishment, cannot occur in a two-country distortion-free Walrasian stable world, see Samuelson (1947). Those paradoxes can occur, however, if (i) there are at least three countries (or agents), see e.g. Gale (1974) or Brecher and Bhagwati (1981), or (ii) if there are domestic distortions, see e.g. Brecher and Bhagwati (1982). The economic intuition for the occurrence of transfer paradoxes, which depends largely on the termsof-trade effect caused by the transfer, can be found in Ohyama (1974), Bhagwati, Brecher, and Hatta (1983, 1985), henceforth referred to as BBH, and Turunen-Red and Woodland (1988). For example, BBH argue

* An earlier version of this paper was presented at the Econometric Society European Meeting in Munich, 1989, and EADI (European Association of Development Research and Training Institutes) in Oslo, 1990. We are grateful to an anonymous referee, Willem Buiter, Peter van Bergeijk, Richard Gigengack, Jan Pen, Georg Tillmann, Edward Tower, and Casper de Vries for helpful comments. 
that (exogenous-type) transfer paradoxes in the three country setting are caused by a "foreign" distortion. By this they mean that the countries directly involved in the transfer (the donor and the recipient) are not using an optimal tariff (are not exploiting their joint monopoly power) vis-à-vis the non-participant. Turunen-Red and Woodland (1988) extend this analysis to an arbitrary number of countries and goods and show that inferiority and/or complementarity are necessary conditions for the existence of strict Pareto improving transfers.

Here we want to point out the remarkable robustness of transfer paradoxes with respect to "endogenization" of transfers. We use the latter term to reflect the empirical observation that transfers are given from rich countries to poor countries and that the size of the transfer is positively related to the donor's income and negatively related to the recipient's income. The positive relation with respect to the donor's income has been formalized, for example, by the United Nations Resolution no. 2626, which states that at least 0.7 percent of rich countries' GNP should be used for development assistance. The negative relation with respect to the recipient's income can be illustrated by the recent proposal of the IGGI countries ${ }^{1}$ to decrease (in real terms) the development assistance given to Indonesia because of its recently flourishing economy. Relations like this make transfers partly endogenous. The recent literature, see e.g. Kemp and Shimomura (1991), Berthélemy (1988), or Turunen-Red and Woodland (1988) and the references therein, has not paid attention to this link between aid and GNP. Berthélemy (1988) notes that "... this literature is on the whole extremely disconnected from policy issues concerning the opportunity of aid and capital transfers to LDCs." (p. 420), but he does not pay attention to the endogenization issue either. We investigate the main consequences of endogenization by modifying the model developed by $\mathrm{BBH}$.

\section{Endogenous Transfers}

Consider a perfectly competitive world with two goods, produced and consumed in three countries. ${ }^{2}$ Country 1 makes a transfer to country 2. Tariffs, quotas, transport costs, and other barriers to trade

1 The InterGovernmental Group on Indonesia, the IGGI, is a group of donor countries that collaborates on development issues with respect to Indonesia.

2 Extension to an arbitrary number of countries is straightforward, see Brakman and van Marrewijk (1989). 
are absent from the model. ${ }^{3}$ The relative price of good $X$ is therefore equal in the three countries. It should be noted that the model can also be applied to represent a transfer from one agent to another within a country. The following notation will be used:

$X, Y \quad$ goods $X$ and $Y$, respectively; good $Y$ is the numéraire; $p \quad$ the relative price of $\operatorname{good} X$;

$u^{i}(X, Y)$ the welfare level of country $i$;

$e^{i}\left(p, u^{i}\right) \quad$ expenditure function of country $i$;

$r^{i}(p) \quad$ revenue function of country $i$;

$c^{i}\left(p, u^{i}\right) \quad$ compensated consumption of good $X$ by country $i$; $x^{i}(p) \quad$ production of good $X$ in country $i$;

$m^{i}\left(p, u^{i}\right) \quad$ import demand for good $X$ by country $i\left(m^{i}=c^{i}-x^{i}\right)$; $T A$

$i$ exogenous (or autonomous part of the) transfer; country index; $i=1,2,3$.

In order to investigate the effects of endogenization we will model endogenization as follows. The total transfer given from country 1 to country 2 consists of two parts; an exogenous part denoted by $T A$, which represents discretionary policy, and an endogenous part. The latter depends on the expenditure level of the donor and is represented by $T\left(e^{1}\left(p, u^{1}\right)\right) .{ }^{4}$ It is assumed that $T$ is a smooth and monotonically increasing function, i.e. the richer the donor gets the larger the transfer it gives. We will use indices to denote derivatives of functions, e.g. $e_{p}^{3}$ is the derivative of country 3's expenditure function with respect to price. Recall, from standard duality theory, that $e_{p}^{i}=c^{i}$ and $r_{p}^{i}=x^{i}$ for all $i$. At the initial equilibrium we normalize the derivative of the expenditure function with respect to utility, $e_{u}^{i}=1$ for all $i$.

The model consists of the following equations

$$
\begin{aligned}
e^{1}\left(p, u^{1}\right)-r^{1}(p)+T\left(e^{1}\left(p, u^{1}\right)\right)+T A & =0, \\
e^{2}\left(p, u^{2}\right)-r^{2}(p)-T\left(e^{1}\left(p, u^{1}\right)\right)-T A & =0, \\
e^{3}\left(p, u^{3}\right)-r^{3}(p) & =0, \\
m^{1}\left(p, u^{1}\right)+m^{2}\left(p, u^{2}\right)+m^{3}\left(p, u^{3}\right) & =0 .
\end{aligned}
$$

Equation (1) says that the donor, country 1, cannot spend more than its earnings minus the transfer given to country 2. Debts and stock-piling are absent from the model. Similarly, equation (2) indicates that the

\footnotetext{
3 On this see for example Bhagwati, Brecher, and Hatta (1985).

4 For a more general description of endogenization see section 3 .
} 
recipient, country 2, can increase its expenditure by the amount of the transfer. Country 3 cannot spend more than it earns [equation (3)]. Finally, equation (4) represents the global market-clearing condition for good $X$ (and hence, by Walras' Law, for good $Y$ ). The model consists of four equations and has four endogenous variables $\left(u^{i}, i=1,2,3\right.$ and $p$ ).

Starting from an initial equlibrium and taking the total differential of (1)-(4) we obtain

$$
\left[\begin{array}{cccc}
1+T_{e^{1}} & 0 & 0 & m^{1}+t \\
-T_{e^{1}} & 1 & 0 & m^{2}-t \\
0 & 0 & 1 & m^{3} \\
m_{u}^{1} & m_{u}^{2} & m_{u}^{3} & m_{p}
\end{array}\right]\left[\begin{array}{c}
\mathrm{d} u^{1} \\
\mathrm{~d} u^{2} \\
\mathrm{~d} u^{3} \\
\mathrm{~d} p
\end{array}\right]=\left[\begin{array}{c}
-1 \\
1 \\
0 \\
0
\end{array}\right] \mathrm{d} T A
$$

where $m_{p} \equiv m_{p}^{1}+m_{p}^{2}+m_{p}^{3}$ and $t \equiv c^{1} T_{e^{1}}$. Obviously the $\mathrm{BBH}$ results can be readily calculated by assuming $T_{e^{1}}=0$ as their model is a special case of ours. After applying Cramer's rule and some manipulations we get

$$
\begin{array}{ll}
\mathrm{d} p / \mathrm{d} T A=\left(m_{u}^{2}-m_{u}^{1}\right) / \Lambda & =(\Omega / \Lambda) \mathrm{d} p /\left.\mathrm{d} T A\right|_{\mathrm{ex}}, \\
\mathrm{d} u^{1} / \mathrm{d} T A=-(\Omega / \Lambda)-m^{1} \mathrm{~d} p / \mathrm{d} T A & =(\Omega / \Lambda) \mathrm{d} u^{1} /\left.\mathrm{d} T A\right|_{\mathrm{ex}}, \\
\mathrm{d} u^{2} / \mathrm{d} T A=(\Omega / \Lambda)-m^{2} \mathrm{~d} p / \mathrm{d} T A & =(\Omega / \Lambda) \mathrm{d} u^{2} /\left.\mathrm{d} T A\right|_{\mathrm{ex}}, \\
\mathrm{d} u^{3} / \mathrm{d} T A=-m^{3} \mathrm{~d} p / \mathrm{d} T A & =(\Omega / \Lambda) \mathrm{d} u^{3} /\left.\mathrm{d} T A\right|_{\mathrm{ex}},
\end{array}
$$

where $\Omega \equiv m^{1} m_{u}^{1}+m^{2} m_{u}^{2}+m^{3} m_{u}^{3}-m_{p}$ and $\Lambda \equiv\left[\left(1+T_{e^{1}}\right)-\right.$ $\left.x^{1} T_{e^{1}} \mathrm{~d} p /\left.\mathrm{d} T A\right|_{\text {ex }}\right] \Omega$. The symbol $\left.\right|_{\text {ex }}$ refers to "exogenous" and is used to identify the exogenous multipliers derived by BBH. Obviously, in the special case of exogenous transfers $(\mathrm{BBH}) \Omega=\Lambda$. It is well known that $\Omega$ equals minus the slope of the general equilibrium excess demand schedule of good $X$ in the exogenous model..$^{5}$ Similar reasoning holds

5 Let $v^{i}$ be the indirect utility function of country $i$. The uncompensated global excess-demand for $X$ is $m^{1}\left(p, v^{1}\right)+m^{2}\left(p, v^{2}\right)+m^{3}\left(p, v^{3}\right)$. If we differentiate this with respect to $p$, using Roy's identity and our normalization, we obtain: $m_{p}^{1}+m_{u}^{1} v_{p}^{1}+m_{p}^{2}+m_{u}^{2} v_{p}^{2}+m_{p}^{3}+m_{u}^{3} v_{p}^{3}=$ $m_{p}-m^{1} m_{u}^{1}-m^{2} m_{u}^{2}-m^{3} m_{u}^{3}=-\Omega$. Requiring $\Omega$ and $\Lambda$ to be positive, and hence stability, makes sense in that a change in a parameter (TA) will bring us back to this stable equilibrium, whereas a change in a parameter starting from an unstable equilibrium would take us to a stable equilibrium according to the global correspondence principle, see Samuelson (1971) or Ide and Takayama (1990). 
for $\Lambda$ with respect to the endogenous model. Walrasian stability requires a price increase in the non-numeraire good if there is an excess demand for that good. This implies therefore that both $\Omega$ and $\Lambda$ are positive. We see clearly, then, from equations (6)-(9) that all the multipliers in the endogenous case are a positive scalar multiple, namely $\Omega / \Lambda$, of the multipliers in the exogenous case. This leads to the following important conclusion:

Proposition 1: Transfer paradoxes (donor enrichment and/or recipient impoverishment) occur in the case of endogenous transfers if and only if they occur in the case of exogenous transfers. The price of $\operatorname{good} X$ rises in the endogenous case iff it rises in the case where transfers are exogenous.

The model displays a remarkable robustness with respect to this type of endogenization. Donor enrichment and recipient impoverishment can still occur but only if it already occurred in the exogenous case. ${ }^{6}$ Even though there is no particular relation between income levels and income derivatives of consumption, which implies transfer paradoxes cannot be ruled out a priori, one would at least expect a change in the conditions under which paradoxes do arise because the welfare and price effects are influenced (i.e. mitigated, see proposition 2) by the endogenous transfer. A possible explanation is given by $\mathrm{BBH}$ who argue that, as mentioned earlier, (exogenous-type) transfer paradoxes in the three country setting used here are caused by a "foreign" distortion. By which they meant that the countries involved in the transfer (the donor and the recipient) are not using an optimal tariff (are not exploiting their joint monopoly power) vis-à-vis the non-participant. As the distortion is still present the transfer paradox should also still occur, as indeed it does.

For obvious reasons we will call $\Omega / \Lambda$ the "multiplier" and say that "dampening" occurs if it is smaller than one. We can now formulate the following proposition:

Proposition 2: Dampening, $\Omega / \Lambda<1$, occurs if and only if the following condition holds:

$$
\mathrm{d} r^{1}(p) /\left.\mathrm{d} T A\right|_{\text {ex }}<1 .
$$

6 In section 3 below we show that the same holds for more general forms of endogenization in which the transfer is also related to the donor's revenue level and the recipient's expenditure or revenue level. 
A sufficient condition for dampening is the absence of price effects, i.e. if the marginal propensity to import good $X$ is the same in countries 1 and 2.

The condition in equation (10) is easy to understand and straightforward to derive. Suppose it does not hold, then transfering one unit of purchasing power results in a revenue increase of more than one unit and thus increases the endogenous transfer.

The absence of price effects (i.e. if $m_{u}^{1}=m_{u}^{2}$; the marginal propensity to import good $X$ is the same in countries 1 and 2) is a sufficient condition for equation (10) to hold. The multiplier then is $\Omega / \Lambda=1 /\left(1+T_{e^{1}}\right)<1$. This effect is not hard to understand either. Suppose country 1 gives 1 extra unit of (autonomous) aid. Its expenditures will have to be reduced by 1 unit while at the same time country 2's expenditure can increase by 1 unit. But then the (endogenous) aid will decrease by $T_{e^{1}}$ units. Country 1 's expenditure will then increase by this amount. Endogenous aid will then increase by $\left(T_{e^{1}}\right)^{2}$ units, etc. Adding up all these transfer changes leads to: $1-\left(T_{e^{1}}\right)+\left(T_{e^{1}}\right)^{2}-\left(T_{e^{1}}\right)^{3}+\ldots=1 /\left(1+T_{e^{1}}\right)$.

\section{Robustness and Conclusions}

We saw in section 2 that in a competitive and Walrasian stable world with two goods transfer paradoxes are robust with respect to endogenization and that endogenization tends to cause a dampening effect (smaller price and welfare changes) provided a revenue condition is fulfilled. In that section we assumed that the endogenous transfers are only related to the donor's expenditure level. It is equally plausible however, as argued above, to relate the transfers to the recipient's expenditure level or to the revenue levels of either country. Here we will see that the results derived in section 2 are very robust with respect to the type of endogenization. Let's analyze the most general formulation in which the endogenous part of the transfer is given by $T=T\left(e^{1}\left(p, u^{1}\right), r^{1}(p), e^{2}\left(p, u^{2}\right), r^{2}(p)\right)$.

Assume that $T$ is smooth, rising in $e^{1}$ and $r^{1}$ (the richer the donor gets the more it gives), decreasing in $e^{2}$ and $r^{2}$ (the richer the recipient gets the less it receives from the donor) and that country 1 will not give away all of its extra earnings or expenditures to country 2 or reduce the amount of the transfer to country 2 by more than country 2 earns or spends additionally, i.e. $0 \leq T_{e^{1}}<1,0 \leq T_{r^{1}}<1,-1<T_{e^{2}} \leq 0$, and $-1<T_{r^{2}} \leq 0$. After making some obvious changes in equations 
(1), (2), and (5) and some elementary calculations it can be shown that the results obtained in equations (6)-(9) still hold provided we redefine $\Lambda$ as $\left[\left(1+T_{e^{1}}-T_{e^{2}}\right) \Omega-\left\{x^{1}\left(T_{e^{1}}+T_{r^{1}}\right)+x^{2}\left(T_{e^{2}}+T_{r^{2}}\right)\right\}\right] \mathrm{d} p /\left.\mathrm{d} T A\right|_{\text {ex }}$. Therefore proposition 3 can be stated as follows:

Proposition 3: The results obtained in propositions 1 and 2 are independent of the type of endogenization, provided that condition (10) is changed to

$$
\begin{aligned}
& \left(T_{e^{1}}+T_{r^{1}}\right) \mathrm{d} r^{1}(p) /\left.\mathrm{d} T A\right|_{\text {ex }}+ \\
& \quad+\left(T_{e^{2}}+T_{r^{2}}\right) \mathrm{d} r^{2}(p) /\left.\mathrm{d} T A\right|_{\text {ex }}<\left(T_{e^{1}}-T_{e^{2}}\right) .
\end{aligned}
$$

Again, the absence of price effects is sufficient for dampening.?

In practice, however, the third, non-participating country will be comprised of all countries not engaged in the transfer. This aggregate country (the rest of the world) will be large in comparison to countries 1 and 2 , making the occurrence of significant price changes due to the transfer most unlikely. Thus we have a strong case for the mitigating welfare effects due to the endogenization of transfers.

\section{References}

Berthélemy, J.-C. (1988): "The Transfer Paradox in a Non-Walrasian Context." Weltwirtschaftliches Archiv 124: 420-434.

Bhagwati, J. N., Brecher, R. A., and Hatta, T. (1983): "The Generalized Theory of Transfers and Welfare: Bilateral Transfers in a Multilateral World." American Economic Review 73: 606-618.

- (1985): "The Generalized Theory of Transfers and Welfare: Exogenous (Policy-imposed) and Endogenous (Transfer-induced) Distortions." Quarterly Journal of Economics 100: 697-714.

7 Equation $\left(10^{\prime}\right)$ gives the combined condition of four separate cases. If the endogenous transfer is exclusively related to the donor's expenditure we get condition (10). If it is exclusively related to the donor's revenue we get $\mathrm{d} r^{1}(p) /\left.\mathrm{d} T A\right|_{\text {ex }}<0$, if exclusively related to the recipient's expenditure $\mathrm{d} r^{2}(p) /\left.\mathrm{d} T A\right|_{\text {ex }}>-1$, and if exclusively related to the recipient's revenue $\mathrm{d} r^{2}(p) /\left.\mathrm{d} T A\right|_{\text {ex }}>0$. These last 3 cases have similar interpretations as given for the first case in section 2 . Note that dampening condition $\left(10^{\prime}\right)$ is stronger than the Walrasian stability condition $\Lambda>0$ [which can be rewritten in the form of $\left(10^{\prime}\right)$ with an identical left-hand-side and " 1 " added to the right-hand-side; i.e. the RHS becomes $\left.\left(1+T_{e^{1}}-T_{e^{2}}\right)\right]$. 
Brakman, S., and Marrewijk, C. van (1989): "Transfer Problems in a Multicountry World: Endogenous, Optimal and Coordinated Aid." Research Memorandum Nr. 297, Institute of Economic Research, University of Groningen.

Brecher, R. A., and Bhagwati, J. N. (1981): "Foreign Ownership and the Theory of Trade and Welfare." Journal of Political Economy 89: 497-511. (1982): "Immiserizing Transfers from Abroad." Journal of International Economics 13: 353-364.

Gale, D. (1974): "Exchange Equilibrium and Coalitions: An Example." Journal of Mathematical Economics 1: 63-66.

Ide, T., and Takayama, A. (1990): "Variable Returns to Scale and the Global Correspondence Principle in the Theory of International Trade." Economics Letters 33: 301-308.

Kemp, M. C., and Shimomura, K. (1991): “Trade' or 'Aid'?" In Trade Policy and International Adjustment, edited by A. Takayama, M. Ohyama, and H. Ohta. New York: Academic Press.

Ohyama, M. (1974): "Tariffs and the Transfer Problem." Keio Economic Studies 11: 29-45.

Samuelson, P. A. (1947): Foundations of Economics Analysis. Cambridge, MA: Harvard University Press.

(1971): "On the Frail of Conventional Beliefs About the Transfer Problem." In Trade, Balance of Payments and Growth, edited by J. N. Bhagwati et al. Amsterdam: North-Holland.

Turunen-Red, A. H., and Woodland, A. D. (1988): "On the Multilateral Transfer Problem." Journal of International Economics 25: 249-269.

Addresses of authors: Dr. Steven Brakman, University of Groningen, Department of Economics, P. O. Box 800, NL-9700 AV Groningen, The Netherlands; Dr. Charles van Marrewijk, Erasmus University Rotterdam, Department of Economics H8-16, P. O. Box 1738, NL-3000 DR Rotterdam, The Netherlands. 